\title{
O Movimento da Sociologia como DisCIPLINA EsCOLAR ENTRE 1925 E 1942: \\ AS ReFormas do SECUNDÁRIO E OS Programas de Ensino do Colégio Pedro II
}

\author{
Wanirley Pedroso Guelfi ${ }^{1}$
}

\begin{abstract}
Resumo
Com esse texto o objetivo norteador foi compreender a inclusão e permanência da Sociologia como disciplina escolar nos currículos do ensino secundário brasileiro entre 1925-1942, na modalidade propedêutica, e sua relação com o ideário da modernidade no país. As fontes pesquisadas foram as leis das reformas do secundário e os programas de ensino do Colégio Pedro II, na cidade do Rio de Janeiro (RJ).

Palavras-chave: Sociologia/Ciências Sociais e ensino secundário. Sociologia/Ciências Sociais e ensino no $2^{\circ}$ Grau. História das disciplinas. História e historiografia da educação.
\end{abstract}

\begin{abstract}
The present text guides to the understanding of the reason why Sociology was inserted and remained as a subject in the Brazilian high school curriculum within the preparatory study category, between 1925 and 1942. Also it aims to understand the connection with the idea of modernity in the country. The sources selected for information was the laws about school legislation and the education programmers of Pedro II College, in Rio de Janeiro, Rio de Janeiro.

Key word: Social Sciences and I teach secondary. Social Sciences and I teach in the 2nd Degree. History of the disciplines. History and historiography of the education.

\footnotetext{
${ }^{1}$ Socióloga, Historiadora e Mestre em Educação. Professora de Metodologia e Prática do Ensino em Ciências Sociais da Universidade Federal do Paraná (UFPR), Setor de Educação (SE), Departamento de Teoria e Prática do Ensino (DTPEN).
} 
A presença da Sociologia como disciplina escolar no ensino secundário brasileiro entre $1925-1942^{2}$ permite, por meio dos programas de ensino e da legislação escolar, estabelecer algumas reflexões acerca dos possíveis porquês da sua inclusão e obrigatoriedade nos currículos da época. Analisando o contexto histórico-cultural do período em questão, e relacionando as mudanças dos conteúdos considerados sociológicos dos programas da disciplina, encontrados no Colégio Pedro II, podemos fazer possíveis leituras sobre sua inclusão e permanência.

Voltando ao período, verificamos que o movimento cultural dos anos 20 e 30 do século XXe as origens do Brasil moderno se confundem num processo histórico marcado por continuidades-descontinuidades que (re)organizou a sociedade brasileira. A educação, entre outras instâncias sociais, não saiu ilesa da rede de relações que alteraram a sociedade brasileira, na tentativa de modernizar o país.

Os currículos e as disciplinas escolares também acompanharam aquelas reorganizações. Por meio do percurso da Sociologia como disciplina escolar no ensino secundário, podem-se visualizar as transformações que ocorriam e, ao mesmo tempo, como a disciplina construiu suas singularidades. Entre 1925-1942 o nível médio do ensino brasileiro passou por duas denominações. De acordo com as diretrizes constantes nos textos das reformas curriculares, entre 1925 e 1929, foi denominado de ginasial e, entre 1929 e 1942, passou a ser denominado de secundário.

Em função das alterações provocadas pelas diferentes diretrizes das reformas educacionais, a organização e o funcionamento do secundário foram modificados. Essas modificações interferiram, inclusive, nas diferentes formas de seleção dos conteúdos que compuseram os programas de ensino. Acompanhando as três reformas legais do período, identificamos três programas diferentes sobre o ensino da Sociologia. E, do ponto de vista legal, constatamos que disciplina foi incluída na primeira, na segunda mantida $\mathrm{e}$ na terceira excluída. Essas reformas ${ }^{3}$ ficaram conhecidas na História da Educação, conforme identifica Sena (1939):

\footnotetext{
${ }^{2}$ A Sociologia como disciplina escolar tem uma trajetória histórica secular. Como disciplina escolar Fundamentado na Legislação, Azevedo (1974) explica que em 1891, com a Reforma Benjamin Constant, "foi incluída uma cadeira de "Sociologia e Moral", no sétimo e último ano da escola secundária, em cujo plano de estudo se introduziu, e na mesma ordem toda a série hierárquica das ciências, segundo a classificação de A. Comte. Mas, além de englobar, numa mesma cadeira, Sociologia e Moral e de reduzir a um semestre o ensino das duas matérias (o que equivale a instituí-lo apenas no papel), essa reforma ou não foi posta em prática ou, no que dizia respeito ao ensino secundário e normal, foi abandonada depois de alterações essenciais".

3 "A implementação de cada programa ocorreu, na maioria das vezes, no mesmo ano ou no ano seguinte ao da reforma” (VECHIA; LORENZ, 1998, p.viii). Portanto, entre 1925 e 1942 pode-se verificar que o ano da reforma e o do programa são diferentes: na Reforma Rocha Vaz, a Lei é de 1925 e o Programa é de 1926. Nas Reformas Francisco Campos (1931) e Gustavo Capanema (1942), os anos da reforma e dos programas são os mesmos.
} 
1ª) Reforma Rocha Vaz: 1925 - Decreto n. ${ }^{0} 16.782$-A de 13 de janeiro de 1925;

$2^{2}$ ) Reforma Francisco Campos: 1931 - Decreto n. ${ }^{0} 19.890$ de 18 de janeiro de 1931;

3a) Reforma Gustavo Capanema: 1942 -Decreto Lei n. 4.244 de 09 de abril de 1942.

Ao longo desse período, entre as reformas principais, foi aprovada uma série de portarias, circulares, decretos, decretos-leis e pareceres, que também interferiram na organização e funcionamento do ensino e dos currículos escolares do secundário. Entre eles, SENA (1939) destaca: 1. ${ }^{\circ}$ ) Decreto n. ${ }^{0} 18.564$, de 15 de janeiro de 1929, que alterou aseriaçã̃o do curso do ensino secundário no Colégio Pedro II, e 2. ${ }^{\circ}$ ) Decreto-Lei n. ${ }^{\circ}$ 1.190, de 4 de abril de 1939, quando ocorre criação e organização da Faculdade Nacional de Filosofia.

Uma compreensão de maior amplitude sobre os significados dessas reformas curriculares no ensino secundário, e a inclusão da Sociologia nesse contexto, implica um retorno, mesmo breve, à constituição estrutural do ensino no Brasil. Romanelli (1998) constata que até os anos 20 nenhuma reforma de caráter nacional havia sido empreendida, e que reformas com esse teor começaram com as Leis Francisco Campos em 1931.

Ainda, segundo a pesquisadora, para se entender a complexidade da educação brasileiraé necessário considerar que a constituição da estrutura educacional relacionase à do social. Portanto, é essencial relembrar a força da tradição do ensino jesuítico e da cultura letrada e bacharelesca e, ao mesmo tempo, relacioná-las à forma como se organizou o poder político, porque este

também se relaciona diretamente com a organização do ensino, em princípio porque o legislador é sempre o representante dos interesses políticos da camada ou facção responsável por sua eleição ou nomeação e atua, naquela organização, segundo esses interesses ou segundo os valores da camada que ele representa. (ROMANELLI, 1998, p.14).

Assim, verifica-se que a herança cultural é influenciada e influi sobre os valores e as escolhas da população que procura a escola. Para Romanelli (1998, p. 14), a crise do sistema educacional brasileiro se manifestou a partir do momento em que essa estrutura começa a ser questionada: fato que ocorreu pelos anos 20. A literatura pesquisada pela autora permitiu-lhe, além de detectar o momento da aceleração da crise dos anos 20, vislumbrar que "as mudanças ocorridas no sistema educacional nos últimos anos ${ }^{4}$ são mais um desfecho de mudanças que começaram a acelerar-se a contar de 1930".

Sempre relacionando fatos do contexto cultural e do educacional, a autora enfatiza

${ }^{4}$ Décadas de 80 e 90 do século XX.

MEDIAÇÕES, LONDRINA, v. 12, N. 1, P. 11-30, JAN/JUN. 2007

- 13 
os anos $30^{5}$ esclarecendo como ocorreram a manutenção e 0 aprofundamento da defasagem existente entre o sistema educacional, de um lado, e a expansão econômica e as mudanças sócio-culturais por que passava a sociedade brasileira, de outro. A maneira pela qual se desenrola o percurso da educação e, portanto, do ensino, reflete a luta existente entre os diversos setores das camadas dominantes, tornando possível identificar "ora a conciliação das facções opostas, ora a predominância de uma delas, sendo a tendência geral favorável às facções conservadoras" (ROMANELLI, 1998, p. 15).

Considerando que as mudanças culturais que ocorriam exigiam uma reorganização da estrutura escolar, a preocupação e as decisões da classe dirigente passaram, naquele momento, pelo conflito do como acompanhar a modernidade mantendo a estrutura tradicional. Nessa perspectiva, Romanelli (1998) sustenta que, se as decisões tomadas favoreceram a facção conservadora, foi porque os mecanismos utilizados para controlar a expansão do ensino foram consistentes. Na interpretação da autora

a predominância dos interesses da facção conservadora, por seu lado, tornou-se responsável por duas formas de controle da expansão do ensino: 1) o controle quantitativo, feito através de dispositivos que criaram uma estrutura rígida, seletiva e discriminante, socialmente falando; 2) o controle qualitativo, que exerceu pelos dispositivos que favoreciam a expansão do ensino de tipo acadêmico e prejudicavam a expansão do ensino técnico. (ROMANELLI, 1998, p. 15).

Observando o percurso da Sociologia como disciplina escolar no período estudado no curso secundário, parece possível estabelecer algumas aproximações entre a lógica da sua dinâmica e a lógica do contexto histórico-cultural abordado por Romanelli (1988), no qual se insere a disciplina. Aproximações que podem esclarecer algumas facetas do processo cultural que possibilitou a inclusão, nos programas de ensino do secundário, de uma disciplina escolar como a Sociologia ${ }^{6}$.

Tendo como referência o contexto cultural abordado e as constatações realizadas por Vechia e Lorenz (1998), épreciso retomar as reformas curriculares citadas pelas quais passou o secundário. E, para acompanhar as mudanças dos conteúdos de Sociologia, buscando compreende-la como disciplina constitutiva dos programas de ensino, passa-se a demonstrar:

\footnotetext{
5 "A contar de 1930, o ensino expandiu-se fortemente, por causa do crescimento sensível da demanda social de educação. 0 crescimento da demanda foi, por sua vez, o resultado de dois fatores concomitantes: o crescimento demográfico e a intensificação do processo de urbanização. 0 primeiro é responsável pelo crescimento da demanda potencial de educação e o segundo, pela evolução dessa demanda, que se torna aos poucos demanda efetiva" (ROMANELLI, 1998, p. 14).

${ }^{6}$ A Sociologia como disciplina escolar, entre 1891 e 1996, é marcada por oscilações, na forma de inclusão, exclusão e indicação, e, associada à modalidade do ensino médio. E, desde Julho de 2006, por lei, passou a ser obrigatória.
} 
1) As reformas desse grau de ensino por meio dos decretos que as legitimam, enfatizando alguns artigos e parágrafos referentes ao Ensino de Sociologia;

2) Os programas de Ensino de Sociologia do Colégio Pedro II.

As diretrizes ${ }^{7}$ da reforma Rocha Vaz foram traçadas pelo DECRETO N. ${ }^{0} 16.782-A$, de 13 de janeiro de 1925, para o ensino secundário superior. Nessa reforma, o secundário foi entendido como um prolongamento do primário, e a Sociologia foi incluída no $6 .^{\circ}$ ano. Do texto do Decreto destaca-se o artigo 48, o parágrafo $2 .^{\circ}$ do artigo 54 e 0 parágrafo $3 .^{\circ}$ do artigo 207, que no livro de Adalberto Corrêa SENA (1939), intitulado Legislação Brasileira do Ensino Secundário, estão nas páginas 212 e 213.

Art. 48 - 0 conjunto de estudos do curso secundário integral compreende as matérias acima discriminadas distribuídas pelas seguintes cadeiras:

Português, até $03^{\circ}$ ano -2 cadeiras.

Português, $4^{0}$ e $5^{\circ}$ anos -2 cadeiras.

Francês -2 cadeiras.

Inglês -2 cadeiras.

Alemão - 1 cadeira.

Latim -4 cadeiras.

Matemática -4 cadeiras.

Geografia -2 cadeiras.

História Universal -2 cadeiras.

História do Brasil -2 cadeiras.

Cosmografia - 1 cadeira.

Instrução Moral e Cívica - 1 cadeira.

Física -2 cadeiras.

Química -2 cadeiras.

História Natural -2 cadeiras.

Filosofia -2 cadeiras.

Literatura - Brasileira e das línguas latinas -2 cadeiras.

Sociologia -1 cadeira (grifo nosso)

0 artigo 54 trata das condições para se conseguir o certificado de conclusão desse grau de ensino, constando no $2 . .^{\circ} \S$ que "ao estudante que fizer o curso do $6 .^{\circ}$ ano e for aprovado em todas as matérias, que o constituem, será conferido o grau de bacharel em ciências e letras". O artigo 207 refere-se às orientações quanto ao preenchimento de vagas e critérios para as matrículas nos cursos superiores, definindo no 3. o $\$$ que "entre os

\footnotetext{
${ }^{7}$ A organização do ensino secundário e do superior é tratada no capítulo VIII, e nas seções terceira e quarta do mesmo capítulo constam os artigos dos programas de ensino (Art. 43 ao 46) e do curso do ensino secundário Art. 47 - 0 ensino secundário como prolongamento do ensino primário, para fornecer a cultura média geral do país, compreenderá um conjunto de estudos com a duração de seis anos. (SENA, 1939, p.211)
} 
aprovados no exame vestibular, terão preferência para a matrícula, independente da ordem de classificação, os bacharéis em ciências e letras".

Lendo na íntegra o texto do Decreto, verifica-se que sobre algumas disciplinas como a História e a Instrução Moral e Cívica, entre outras, constam algumas orientações e/ou comentários quanto: à importância, ao significado da seleção de determinados conteúdos, e alguns aspectos relacionados à metodologia dessas disciplinas. Mas, sobre a Sociologia consta somente a indicação da disciplina no $6 .^{\circ}$ ano. Mais uma vez, entendese que essa ausência de indicativos metodológicos se explica pelas dificuldades de uma disciplina escolar recente em estabelecer suas fronteiras, seus métodos e seus conteúdos. A seleção dos conteúdos constantes nos programas da disciplina indica essas dificuldades.

0 primeiro programa da "Cadeira de Sociologia" do Colégio Pedro II, entre 1926 e 1928, foi organizado em duas partes: $1^{a}$ ) Sociologia Theorica e 2a) Fontes históricas da Sociologia. Cada uma delas é composta por conteúdos (quadro 1).

Por meio da organização dos conteúdos selecionados, neste programa, podem ser identificadas algumas questões pertinentes à Sociologia como uma ciência em constituição no Brasil. Observando-se os conteúdos listados, constata-se que havia uma preocupação em ratificar a Sociologia como uma ciência específica, no tema denominado Sociologia Theorica. Mas, ao mesmo tempo, houve um predomínio dos conteúdos de História, na listagem que organiza o tema Fontes históricas da Sociologia.

Buscando identificar a especificidade da Sociologia, verificam-se, nos manuais didáticos da década de 1930, citados nas referências bibliográficas, as dificuldades existentes em conceituar o que é, qual o seu objeto de estudo e metodologia de pesquisa. Constatase uma consciência sobre a Sociologia como uma ciência em construção e a ênfase, apesar das polêmicas, em situá-la como um conjunto de conhecimentos específicos, entre as Ciências Humanas. Identificam-se também dificuldades em conceituar a disciplina. Para alguns autores, a Sociologia tinha um referencial teórico próprio, para outros ela era apenas disciplina prática, e outros a entendiam como arte.

São visíveis também as questões confusas relativas à organização de conteúdos específicos e aos métodos da Sociologia, porque ao organizá-los percebem-se determinados conteúdos pertinentes à História ${ }^{8}$, à Filosofia ${ }^{9}$, à Antropologia ${ }^{10}$ e à Política ${ }^{11}$, e uma metodologia semelhante à da História. Entre os conteúdos, destacam-se as dificuldades à aplicabilidade prática dessa nova ciência.

\footnotetext{
${ }^{8}$ Entre eles citamos: Os impérios; A civilização romana: A idade Média e o regime feudal.

${ }^{9}$ Identificamos: Sofismas e erros; Filosofia da História; Dualidade do homem egoísta e social; Gênese dos sentimentos coletivos; sociologia especulativa e teleológica.

${ }^{10}$ São conteúdos associados à Antropologia: Humanidade gregária; Extensão e desenvolvimento do regime da família; herança, seu caráter primitivamente religioso; Estado primitivo e promiscuidade; misticismo das coletividades.

${ }^{11}$ Alguns conteúdos estão mais próximos de uma discussão política: 0 Estado; formas de governo; monarquia; aristocracia; democracia; república, Divisão dos poderes executivo, legislativo e Judiciário.
} 


\begin{tabular}{|c|c|}
\hline \multicolumn{2}{|r|}{ PROGRAMA } \\
\hline Parte & Conteúdo \\
\hline $1^{a}$ & 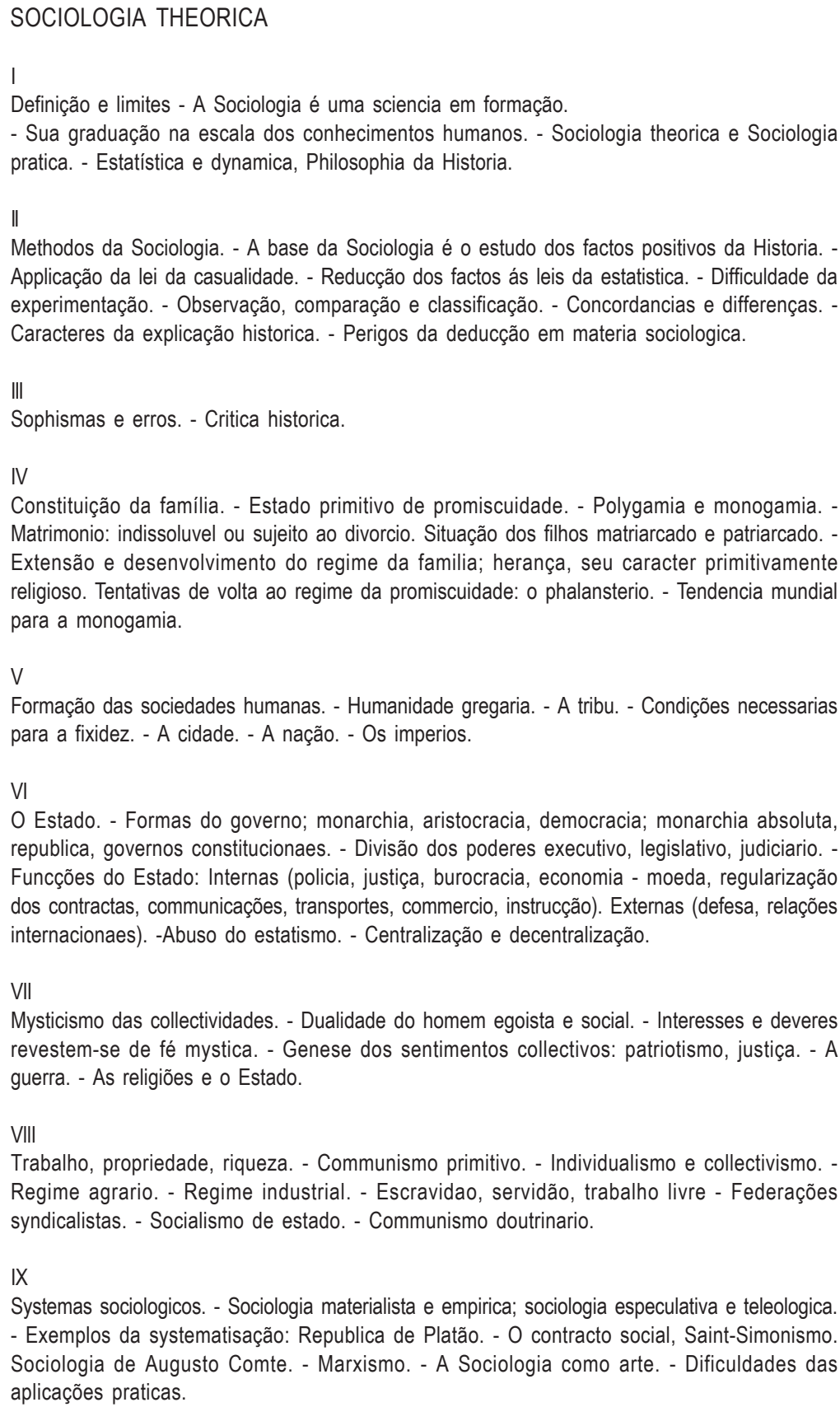 \\
\hline
\end{tabular}


$x$ Formação e evolução da civilisação mediterranea. — Origens asiaticas. - Civilisação egypcia. Transição phenicia e egea. - Caracteres geraes da civilisação mediterranea. Dissidencia judaica. $\mathrm{XI}$

Caracteres da civilisação grega. - A familia, a educação. situação da mulher. - A cidade, suas bases religiosas; sua extensão; colonias. - Solidariedades e rivalidades; Amphyctionais. - A religião. - As organisações políticas. - Contrastes da civilisação grega e da civilisação oriental. -0 choque do $\mathrm{V}$ seculo. $-\mathrm{A}$ decadencia.

XII

A civilisação romana. - A organisação familiar. - Rivalidade das classes e tendencia para 0 equilibrio. - As lutas agrarias e a constituição do latifundio. - Augusto e seus esforços para a volta ás tradições. - Evolução da cidade para 0 imperialismo mundial. - Poder e flexibilidade do direito romano. - Motivos da decadencia.

XIII

0 advento do christianismo. Sua evolução nos Ires primeiros seculos e sua adaptação ao regime social que acaba dominando. A absorpção dos barbaros na civilisação mediterranea.

XIV

A Idade Media e o regime feudal. $-\mathrm{A}$ constituição das grandes nacionalidades. -0 equilibrio dos dois gladios. - A lucta do espiritual e do temporal. - A tendencia para o absolutismo politico.

$\mathrm{XV}$

Causas da Renascença. - Resultados economicos e políticos das descobertas maritimas. Modificações nas crenças. -0 Humanismo. - A Reforma. -0 triumpho do absolutismo. 0 tradicionalismo familial e religioso.

$\mathrm{XVI}$

O Seculo XVIII e o encyclopedismo. - As novas concepções sociaes. - A crise revolucionaria e a dictadura imperial. - A reação tradicionalista. - A victoria da democracia.

XVII

Revolução economica do seculo XIX. - A grande indústria e o poder da burguesia. - A lucta proletaria.

XVIII

A crise de 1914. - A anarchia economica e social contemporânea. - Tendencia para o indíduaslismo na familia e o socialismo no estado. - A experiencia russa. - Resultados da política colonial do ultimo seculo. -0 esforço para a creação de uma moral internacional.

XIX

Canalisação da civilisação mediterranea na America Latina -Mentalidade dos descobridores e conquistadores. -0 aniquilamento das duas grandes civilisações autochonas. -0 monopolio administrativo e commercial das metropoles. - A evolução da família no Novo Continente. Formação economica do espírito nativista - Sua eclosão mystica. - Sua realisação revolucionaria. - Seu desenvolvimento realista e pacifico. - Filiação mental ao espírito europeu na procura da originalidade nacional, esthetica e social

$\mathrm{xx}$

Originalidade da formação brasileira. - A influencia do meio extenso e variado. — Organisação da producção colonial; escravisação india do typo duro e negra do typo branco e familiar. - 0 movimento constitucional do XIX seculo que redundou na creação de uma monarchia americana já anachronica. - A transformação republicana e federativa. - Situação actual no concerto mundial.

Quadro 1 - Cadeira de Sociologia - 1925 
Em síntese, pode-se afirmar que esses indicativos sinalizam que a Sociologia, naquele contexto histórico, mesmo buscando enfaticamente uma identidade própria, tinha ainda como referência para delimitar suas fronteiras as demarcações das disciplinas citadas. Portanto, predominaram nesse programa do ensino médio conteúdos já consolidados em outras disciplinas.

Esse programa foi modificado em 1929 pelo Decreto n. ${ }^{0} 18.564$ - de 15 de janeiro de 1929 - porque, conforme diz o título, ele "altera a seriação do curso do ensino secundário no Colégio Pedro II”. Da seriação organizada, segundo os novos encaminhamentos legais, constantes no artigo $1 .^{\circ}$ do Decreto, destaca-se a do $6 .{ }^{\circ}$ ano do curso complementar, no qual a Sociologia, entre outras disciplinas, foi mantida.

Nessa nova orientação, as disciplinas selecionadas para $06 .^{\circ}$ ano foram organizadas da seguinte maneira: "1) Sociologia (grifo nosso);2) História da Filosofia;3) Literatura (especialmente a brasileira e as línguas latinas); 4) Italiano (facultativo); 5) Curso complementar de Matemática para os alunos que se destinam às escolas Militares e Politécnica; 6) Curso complementar de Geografia (Social e Econômica)" (SENA, 1939).

Sobre essas alterações, Machado (1987) constata que "as modificações promovidas pelo Dec. ‥ ${ }^{0}$ 18.564, de 15 de janeiro de 1929, no curso secundário não alteraram essa situação", referindo-se à permanência da Sociologia como disciplina escolar. Mas, no programa do ensino de Sociologia do Colégio Pedro II, comparadas com as do programa anterior, as alterações foram significativas. A organização foi dividida em cinco temas compostos por uma determinada seleção de conteúdos, conforme demonstra o quadro 2. Os temas articuladores dos conteúdos foram: I - As Theorias Sociologicas; II - As Sociedades Humanas; III-A Psycologia Social; IV-As Instituições e V-Osproblemas sociaes contemporâneos.

Comparando-se o programa de 1925 com o de 1929, percebe-se que os conteúdos propostos no último são mais próximos e específicos da Sociologia. Essa diferença retrata avanços nos estudos sociológicos no país. Nesse programa, predominaram conteúdos contemporâneos à época, identificando-se uma preocupação com os problemas nacionais. Mas, uma preocupação que envolvia, não apenas as reflexões sobre os problemas, mas prioridades e ações para enfrentá-los ${ }^{12}$.

Nessa ótica, os estudos sociológicos poderiam contribuir com "soluções adequadas" os problemas sociais detectados por meio da pesquisa. As pesquisas permitiriam pensar os encaminhamentos para "as soluções" necessárias. Tratava-se de "soluções" fundamentadas na "ciência nova": a Sociologia.

\footnotetext{
${ }^{12}$ Problemas de ordem social tais como: greves; organização dos trabalhadores; desemprego; movimentos anarquistas e socialistas no interior da organização política dos trabalhadores.
} 


\begin{tabular}{|c|c|c|c|c|}
\hline \multicolumn{5}{|c|}{ CONTEÚDOS } \\
\hline $\begin{array}{l}\text { I-As theorias } \\
\text { Sociologicas }\end{array}$ & $\begin{array}{l}\text { II - As Sociedades } \\
\text { Humanas }\end{array}$ & $\begin{array}{l}\text { III - A Psychologia } \\
\text { Social }\end{array}$ & IV - As Instituições & $\begin{array}{l}\text { V-Os problemas sociaes } \\
\text { contemporaneos }\end{array}$ \\
\hline $\begin{array}{l}\text { 1. Generalidades - } \\
\text { Objecto e } \\
\text { definições. } \\
\text { 2. Os fundadores da } \\
\text { Sociologia: Comte. } \\
\text { Spencer. } \\
\text { 3. Principaes escotas } \\
\text { sociologicas } \\
\text { modernas. } \\
\text { 4. A theoria das torças } \\
\text { sociaes. }\end{array}$ & $\begin{array}{l}\text { 5. Influencias do meio. } \\
\text { 6. Formação e fixação } \\
\text { dos grupos. } \\
\text { 7. Os problemas } \\
\text { demographicos } \\
\text { 8. A questão das } \\
\text { raças. } \\
\text { 9. As migrações } \\
\text { humanas -A } \\
\text { immigração. }\end{array}$ & \begin{tabular}{|l} 
10. Evolução \\
organica e \\
cultural. \\
11. Psychologia \\
collecliva.
\end{tabular} & $\begin{array}{l}\text { 12. A familia - Origens e } \\
\text { modalidades. } \\
\text { 13. A moral - A religião } \\
\text { - A lgreja. } \\
\text { 14. O Direito e a Lei. } \\
\text { 15. O Estado e suas } \\
\text { funç̧ões. } \\
\text { 16. A linguagem - A arte, } \\
\text { sua expressao. } \\
\text { 17. Estructura economica } \\
\text { da Sociedade. }\end{array}$ & $\begin{array}{l}\text { 18. Anormaes, retardados e } \\
\text { defeituosos. } \\
\text { 19. Pauperismo e miséria. } \\
\text { 20. Alcoolismo - Vícios sociaes. } \\
\text { 21. A protecçao dos menores- } \\
\text { Os delinquentes. } \\
\text { 22. O crime e sua repressão. } \\
\text { 23. O trabalho e o desemprego - } \\
\text { Accidentes } \\
\text { 24. Migrações urbanas } \\
\text { 25. Os problemas da comunidade } \\
\text { 26. Saude publica e hygiene. } \\
\text { 27. Obras de melhoramento social. } \\
\text { 28. O papel da educação. } \\
\text { 29. Guerra, paz e } \\
\text { internacionalismo. } \\
\text { 30. O progresso social. }\end{array}$ \\
\hline
\end{tabular}

Quadro 2 - Programa do Ensino de Sociologia - 1929

Por meio dos conteúdos selecionados para o programa de 1929, apreendem-se os valores que deveriam ser implantados na sociedade onde "o progresso social" era a meta. Ao mesmo tempo em que os conteúdos permitiam indicar os problemas, mediados por "atitudes científicas" para conseguir cumprir a meta, eles revelam, implicitamente, quais os sujeitos e valores excluídos na sociedade brasileira.

Conteúdos como "o papel da educação"; "a proteção dos menores: os delinqüentes"; "alcoolismo: vícios sociais"; "Influência do meio"; "a questão das raças"; "evolução orgânica e cultural"; "anormais, retardados e defeituosos", identificam os valores que predominaram e os sujeitos excluídos naquele contexto histórico.

Por meio deles, podem ser identificados também, além dos temas sociológicos e de conteúdos pertinentes à Geografia ${ }^{13}$, conteúdos referentes à Educação. Neste, a educação escolar foi abordada como uma, entre outras, Instituição Social. 0 tema passou a constar como um conteúdo escolar específico. Associando esta referência de conteúdo específico da Sociologia ao contexto onde se insere, revela-se a ênfase na valorização da educação escolar.

Apesar das mudanças dos programas, a Sociologia foi mantida como disciplina escolar obrigatória. Mas, foi a partir da Reforma Francisco Campos, em 1931, que a mesma passou a ter uma configuração semelhante àquelas disciplinas consolidadas ${ }^{14}$.

${ }^{13}$ Conteúdos como: Influência do meio; os problemas demográficos; as migrações humanas.

${ }^{14}$ A História e a Geografia são exemplos de disciplinas consolidadas na época. 
Ou seja, ocorreu naquela década uma conjunção de elementos culturais necessários à consolidação de uma disciplina em constituição, porque já havia:

a) Um vocabulário sociológico veiculado entre os intelectuais atingindo, provavelmente, um grupo ${ }^{15}$ maior da sociedade que se urbanizava, em especial, em São Paulo e Rio de Janeiro ${ }^{16}$;

b) Uma expansão de publicação de livros didáticos de Sociologia;

c) Uma regularidade de 06 (seis) anos da disciplina no secundário; ${ }^{17}$

d) Uma relação com a constituição/consolidação das Ciências Sociais e, portanto da Sociologia, no ensino superior com a fundação da Escola Livre de Sociologia e Política da São Paulo (ELSP) em 1933, e da Faculdade de Filosofia Ciências e Letras (FFCL) em 1934.

Considerando esse quadro, os anos 30 foram decisivos para a consolidação da Sociologia como campo de pesquisa e de ensino de nível superior, e entende-se que a Reforma Francisco Campos foi um dos componentes culturais constitutivos daquele processo. Esse entendimento se fundamenta na justificativa de que essa reforma enfatizou o ensino secundário propedêutico e o superior. Afinal, era necessário formar professores para os cursos secundários e formar intelectuais atualizados. 0 conhecimento sociológico era parte dessa formação atualizada. A disciplina de Introdução a Sociologia, por exemplo, fez parte dos currículos do primeiro ano dos cursos de Medicina e Direito.

Em 1931, através do Decreto n. ${ }^{0} 19.890$ - de 18 de abril de 1931 - foi estabelecido no Art. $2 .{ }^{\circ}$ que o ensino secundário compreenderia dois cursos seriados: o fundamental com cinco anos de duração (quadro 3) e o complementar com dois (quadro 4).

As diretrizes da Reforma Francisco Campos traçadas para o nível médio mantiveram, no complementar, a Sociologia como disciplina obrigatória. As orientações relativas ao funcionamento do curso complementar estão no Art. $4{ }^{\circ}$ do decreto promulgado em 1931.

0 curso complementar é obrigatório para os candidatos à matrícula em determinados institutos de ensino superior, será feito em dois anos de estudo intensivo, com exercícios

\footnotetext{
${ }^{15}$ Provavelmente, esse vocabulário passou a circular para além do círculo dos intelectuais, entre: 1) trabalhadores imigrantes com idéias socialistas, anarquistas e integralistas já veiculadas na Europa; 2) Professores do primário, através da Sociologia da Educação; 3) alunos do curso primário, através dos conteúdos de Estudos Sociais: Pátria, Nação, Progresso, Família, entre outros.

${ }^{16}$ Devem-se considerar, naquele contexto, outros meios pelos quais foram veiculados o vocabulário sociológico: 1937 (INL); 1938 - A Hora do Brasil era irradiada por todas as rádios do país; 1938 - Criação da CNLD; 1939 - Criação do DIP pelo Decreto-lei no 1915 de 27/12/1939.

${ }^{17}$ Considerando que a Reforma Rocha Vaz data de 1925, mas o programa do ensino foi implantado em 1926.
} 
e trabalhos práticos individuais e compreenderá as seguintes matérias: Alemão ou Inglês, Latim, Literatura, Geografia, Geofísica e Cosmografia, História da Civilização, Matemática, Física, Química, História Natural, Biologia geral, Higiene, Psicologia e Lógica, Sociologia, Noções de Economia e Estatística, História da Filosofia e Desenho (BRASIL, 1932).

\begin{tabular}{|c|l|}
\hline \multicolumn{2}{|c|}{ CURSO FUNDAMENTAL } \\
\hline Série & \multicolumn{1}{c|}{ Disciplinas } \\
\hline $1^{\text {a }}$ & $\begin{array}{l}\text { Português - Francês - História da Civilização - Geografia - Matemática - Ciências físicas e naturais - } \\
\text { Desenho - Música (canto orfeônico) }\end{array}$ \\
\hline $2^{\text {a }}$ & $\begin{array}{l}\text { Português - Francês - Inglês - História da Civilização - Geografia - Matemática - Ciências físicas e } \\
\text { naturais - Desenho - Música (canto orfeônico) }\end{array}$ \\
\hline $3^{\text {a }}$ & $\begin{array}{l}\text { Português - Francês - Inglês - História da Civilização - Geografia - Matemática - Física - Química - } \\
\text { História Natural - Desenho - Música (canto orfeônico) }\end{array}$ \\
\hline $4^{\text {a }}$ & $\begin{array}{l}\text { Português - Francês - Inglês - Latim - Alemão (facultativo) - História da Civilização - Geografia - } \\
\text { Matemática - Física - Química - História Natural - Desenho }\end{array}$ \\
\hline $5^{\text {a }}$ & $\begin{array}{l}\text { Português - Latim - Alemão (facultativo) - História da Civilização - Geografia - Matemática - Física - } \\
\text { Química - História Natural - Desenho }\end{array}$ \\
\hline
\end{tabular}

Quadro 3 - Curso Fundamental e as Disciplinas Obrigatórias nas Cinco Séries - 1931 NOTA: De acordo com as orientações constantes no Art. $3^{\circ} 0$ alemão foi a única disciplina facultativa, as demais disciplinas eram de caráter obrigatório.

\begin{tabular}{|l|l|l|l|l|l|}
\hline \multicolumn{5}{|c|}{ DISCIPLINAS OBRIGATÓRIAS } \\
\hline \multicolumn{2}{|c|}{ Direito (1) } & \multicolumn{1}{|c|}{ Medicina, Odontologia e Farmácia (2) } & \multicolumn{2}{c|}{ Engenharia e Arquitetura (3) } \\
\hline $1^{\circ}$ Ano & \multicolumn{1}{|c|}{$2^{\circ}$ Ano } & \multicolumn{1}{|c|}{$1^{\circ}$ Ano } & \multicolumn{1}{c|}{$2^{\circ}$ Ano } & $1^{\circ}$ Ano & \multicolumn{1}{c|}{$2^{\circ}$ Ano } \\
\hline Literatura & Literatura & Alemão/Inglês & Alemão/Inglês & $\begin{array}{l}\text { Psicologia e } \\
\text { Lógica }\end{array}$ & $\begin{array}{l}\text { Sociologia (grifo } \\
\text { nosso) }\end{array}$ \\
\hline Latim & Latim & Psicologia e Lógica & $\begin{array}{l}\text { Sociologia (grifo } \\
\text { nosso) }\end{array}$ & Matemática & Matemática \\
\hline $\begin{array}{l}\text { Psicologia e } \\
\text { Lógica }\end{array}$ & $\begin{array}{l}\text { Sociologia } \\
\text { (grifo nosso) }\end{array}$ & Matemática & Física & Física & Física \\
\hline $\begin{array}{l}\text { Noções de } \\
\text { Economia e } \\
\text { Estatística }\end{array}$ & Higiene & Física & Química & Química & Química \\
\hline Biologia Geral & Geografia & Química & História Natural & História Natural & História Natural \\
\hline História & História & História & & $\begin{array}{l}\text { Geofísica e } \\
\text { Cosmologia }\end{array}$ & Desenho \\
\hline & Filosofia & & & & \\
\hline
\end{tabular}

Quadro 4 - Curso Complementar, Para os Cursos de Direito, Medicina, Farmácia,

Odontologia, Engenharia e Arquitetura -1931

FONTE: Xavier et al. (1994, p. 192).

NOTA: (1) Conforme Art. 5; (2) Conforme Art. 6; (3) Conforme Art. 7, pode-se verificar como foi organizada a distribuição das disciplinas obrigatórias pelos dois anos do curso complementar. 
Os artigos 5. $.^{\circ}, 6 .^{\circ}$ e $7 .^{\circ}$ indicam como foi organizada a distribuição das disciplinas obrigatórias pelos dois anos do curso complementar, para os candidatos que almejavam ingressar nos cursos: Jurídico; Medicina, Farmácia e Odontologia; Engenharia e Arquitetura, nos quais a Sociologia foi incluída somente no $2{ }^{\circ}$ ano. 0 quadro 3 permite visualizar como foi estruturado o curso complementar.

A lei passou a vigorar no mesmo ano de Decreto, portanto suas diretrizes valiam para os alunos que ingressaram no secundário em 1931. Permanecendo no secundário, eles teriam contato com a disciplina somente em 1937. Sobre essa situação, Machado (1987) demonstra que os alunos em curso - anterior à data do Decreto - prosseguiriam de acordo com a legislação anterior, e, nesse caso, os programas seriam "os adotados pelo Colégio Pedro II, em 1930" - conforme o artigo 83 do Decreto n. ${ }^{\circ} 19.890 / 31^{18}$ e artigo 94 do Decreto n. $^{0} 21.241 / 32^{19}$. Tendo como referência esses decretos ${ }^{20} 0$ autor em sua pesquisa, constata que

para a Sociologia, a carga horária semanal era de quatro horas para os candidatos aos Cursos Jurídicos, de três horas para os candidatos aos cursos de Medicina, Farmácia e Odontologia, e de três horas para os candidatos aos cursos de Engenharia, Química Industrial e Arquitetura. 0 programa da disciplina era 0 mesmo para as três modalidades de curso complementar e constava de quarenta e quatro tópicos distribuídos em três partes: 'Introdução' (tópicos I a VIII), 'Origens Sociais' (tópicos IX a XVI) e 'Estrutura Social' (tópicos XVII a XLIV) (MACHADO, 1987, p 121).

Mas o programa de ensino pensado em 1931 começou a ser implantado nas escolas secundárias a partir de 1939. Segundo o programa, o ensino da disciplina foi organizado em três partes, e cada uma delas foi composta por um grupo de "Lições de Sociologia", conforme indica o quadro 5.

Os Decretos de 1931-32, o conteúdo dos quadros 3 e 4 e as afirmativas de Machado (1987) sinalizam que a Sociologia no secundário passou a ter uma visibilidade maior como disciplina escolar a partir de 1937. Mas, ao mesmo tempo, essa visibilidade não se consolida, porque através da Reforma Capanema - Decreto-lei n. ${ }^{\circ}$ 4.244, de 9 de abril de 1942 - 0

\footnotetext{
18 "Art.83 - A presente reforma se aplicará imediatamente aos alunos da primeira série do ensino secundário, prosseguindo os das demais séries o curso na forma da legislação anterior a este Decreto e ficando para se matricularem nos cursos superiores, sujeitos a exame vestibular.

$\S 1^{\circ}$ - Os programas dos cursos a serem feitos de acordo com a seriaçã̃o da legislação anterior serão adotados pelo Colégio Pedro II em 1930, salvo o de Matemática."

19 "Art.94 - Os alunos do regime seriado que neste ano letivo, se matricularem na $3^{\mathrm{a}}$, na $4^{\mathrm{a}} \mathrm{e}$ na $5^{\mathrm{a}}$ série do ensino secundário prosseguirão o curso de acôrdo com a seriação da legislação anterior. "

${ }^{20}$ Esses decretos estão relacionados no livro de Joaquim de Campos Bicudo intitulado "0 ensino secundário no Brasil e sua atual legislação" (de 1931 a 1941 inclusive) e publicado em 1942.
} 
secundário passa por outra mudança, e as diretrizes traçadas alteraram os programas de ensino. Nessas alterações, a Sociologia foi excluída como disciplina obrigatória.

\begin{tabular}{|c|c|}
\hline \multicolumn{2}{|r|}{ PROGRAMA } \\
\hline Parte & Conteúdo \\
\hline Introdução & $\begin{array}{l}\text { I - Sociologia: conceito e definição. A Sociologia no quadro geral dos conhecimentos } \\
\text { humanos. } \\
\text { II - Objeto da sociologia. Fato social: conceituação e definição. Classificação dos fatos } \\
\text { sociais. } \\
\text { III - Esboço histórico da sociologia, seus antecedentes. Desenvolvimento da sociologia em } \\
\text { França, na Inglaterra e na Alemanha. A Sociologia nos E.U. da América do Norte. Literatura. } \\
\text { IV - Relações da sociologia com as ciências conexas. Filosofia social e sociologia. } \\
\text { Filosofia moral e Sociologia. Sociologia psicanalítica. Sociologismo e psiclgismo. } \\
\text { V - Metodologia socilógica; natureza e processos. Escolas sociológicas: sua classificação. } \\
\text { VI - Escolas positiva, evolucionista e socialista. Escola de Durkheim. } \\
\text { VII- Escolas de reforma social, de ciência social e economia social. Escola hitórico-cultural. } \\
\text { VIII - Sociólogos norte-americanos; variedade de tendências. Sociólogos brasileiros e } \\
\text { latino-americanos. }\end{array}$ \\
\hline $\begin{array}{l}\text { Origens } \\
\text { sociais }\end{array}$ & $\begin{array}{l}\text { IX - Exposição geral do problema da formação dos grupos sociais primitivos. Origem do } \\
\text { homem segundo o gênese. A monogamia como forma primitiva da família. Os patriarcas e } \\
\text { o regime da poligamia. Restabelecimento da monogamia pelo cristianismo. } \\
\text { X - Teorias evolucionistas sobre a origem do homem e a formação da família. Origem das } \\
\text { espécies, segundo o monismo. Promiscuidade primitiva humana. Matriarcado - Patriarcado. } \\
\text { A monogamia como produto da evolução social. } \\
\text { XI - as origens sociais à luz da etnologia moderna. A tese de Durkheim: sua conceituação } \\
\text { de família. Clan totêmica, ponto de partida da evolução da família. Doutrina da escola } \\
\text { histórica-cultural: sua base. } \\
\text { XII - A propriedade entre os povos primitivos. As formas primitivas da propriedade segundo } \\
\text { E. de Laveleye. Contestação da inexistência da propriedade privada entre os povos } \\
\text { primitivos. } \\
\text { XIII - A religião entre os povos primitivos. Conceito da religião. Religião natural e religião } \\
\text { revelada. Classificação das religiões. A ciência das religiões comparadas e as investigações } \\
\text { sobre a religião da pre-história. Confrontos das teorias de Durkheim, de Frazer, etc., e da } \\
\text { escola histórico-cultural. (P. Schimidt - H. Pinard de la Boullaye, etc.). } \\
\text { XVI - A lei moral e os primitivos. A moralidade nos grupos sociais primitivos. Conexões } \\
\text { entre a moralidade primitiva e a religião. Divergência de apreciação dos dados etnológicos } \\
\text { pelas diversas escolas sociológicas quanto à moralidade dos povos primitivos. } \\
\text { XV - Ciências especulativas e normativas. Moral e Sociologia. A ciência dos costumes de } \\
\text { Lévy-Bruhl: a firmação de conflito com a moral teórica. Crítica de Simon Deploige. } \\
\text { XVI - Postulados da Sociologia. Postulados e hipóteses. Postulados da Sociologia católica } \\
\text { segundo Spalding. Os postulados fundamentais de Durkheim. Postulados da Sociologia } \\
\text { naturalista. }\end{array}$ \\
\hline
\end{tabular}




\begin{tabular}{|c|c|}
\hline & 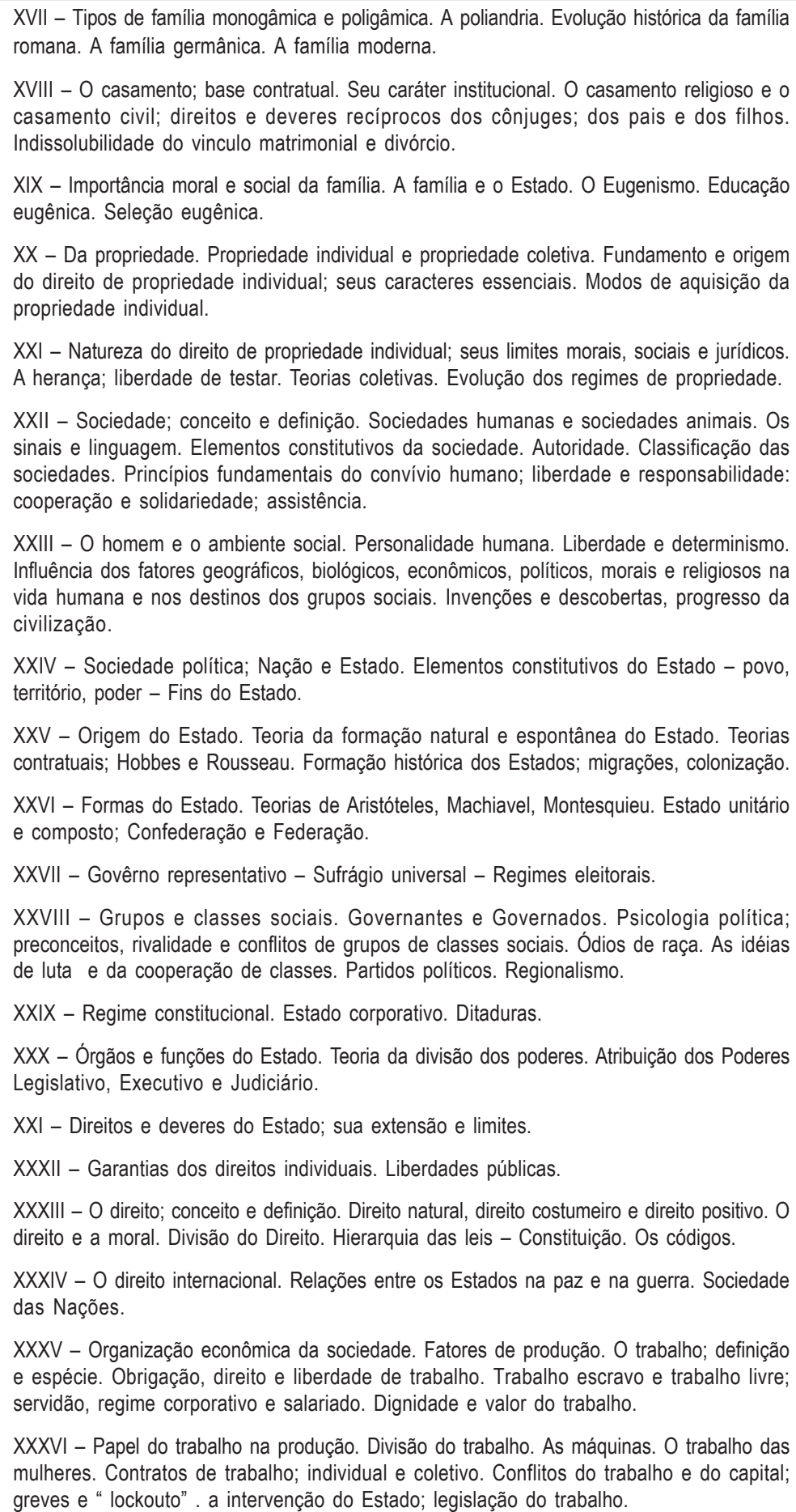 \\
\hline
\end{tabular}




\begin{tabular}{|l|l|}
\hline XXXVII - Remuneração do trabalho; suas formas. O salário; suas categorias. Vantagens e \\
inconvenientes do salariado. O justo salário e o salário mínimo. Medidas de proteção contra \\
a insuficiência do salário. O desemprego e a assistência do Estado. \\
XXXVIII - Associações profissionais. Direito de associação. Sindicatos; obrigatórios, livres. \\
Unidade e pluralidade sindical; princípio de autonomia. Representações profissionais e \\
organização política do Estado. Cooperativas e mutualidades. \\
XXXIX - O capital; conceito e definição. Papel do capital na produção. Remuneração do \\
capital o regime capitalista. Abusos do capital; usura, especulação e agiotagem. Conciliação \\
dos direitos do capital e do trabalho; justiça social. Influência das transformações econômicas. \\
XL - A Igreja e o Estado. União e separação da Igreja e do Estado; regime de colaboração \\
recíproca. As concordatas. Liberdade religiosa, cultor externo. As associações religiosas. \\
Influência social da religião. A religião e a ciência. A religião e as artes. \\
XLI - Instrução e educação. Direito à educação e dever de ministrá-la. Liberdade de ensino. \\
A família e a escola. O Estado e a Igreja no domínio da educação. Ensino religioso e \\
laicismo. \\
XLII - Valor da educação para o progresso social. A estrutura do ensino; ramos e gráus. \\
Obrigatoriedade escolar. Gratuidade do ensino. Regulamentação do ensino pelo Estado. \\
XLIII - O problema da população e a teoria de Malthus. Tendência atual para o decréscimo \\
da natalidade e prolongamento da vida humana; suas causas e consequências. Países \\
super-povoados - emigração. Reivindicação de espaço (matérias primas) - colonização. \\
Países novos; política de povoamento do solo. Imigração e razões da sua regulamentação \\
restritiva. \\
XLIV - Sociologia criminal. O problema do crime e da pena. Responsabilidade moral e \\
responsabilidade social (determinismo). Causas do crime. Fundamento do direito de punir. \\
Finalidade da pena. Estatística criminal. \\
\hline
\end{tabular}

Quadro 5 - Programa Integral dos Cursos Complementares - 1939 Fonte: PROGRAMA INTEGRAL DOS CURSOS COMPLEMENTARES (1939, p. 42-46).

O percurso da disciplina, através das Legislações do ensino secundário e dos Programas de Ensino do Colégio Pedro II, relacionado ao movimento da dinâmica social, evidencia sua singularidade e, ao mesmo tempo, o situa na rede de relações culturais de uma época. A hierarquização, seleção e exclusão de determinados conteúdos dos programas de ensino estão intimamente interligadas às mudanças culturais da sociedade.

Se no primeiro programa predominam conteúdos da História, no segundo há uma preocupação com os problemas contemporâneos e no terceiro é perceptível uma preocupação com os conteúdos que explicitem a questão do Estado, da Nação, da família, da religião. Além desses conteúdos que se destacaram entre os demais, foi incluído um conteúdo específico: o da Sociologia Criminal21 ${ }^{21}$. Esse conteúdo sugere a preocupação com a questão da mestiçagem no Brasil, como um problema social.

Portanto, o movimento de uma disciplina escolar revela a dinâmica da sociedade onde está incluída. No caso da modernidade brasileira, um dos grandes desafios que a classe dirigente enfrentou nesse período foi modernizar um país onde faltavam, segundo Serva (1924), "as qualidades que actualmente prevalecem nos povos modernos: capacidade

${ }^{21}$ Ver Lição XLIV do programa do ensino de sociologia de 1939. 
pratica, pessoal thecnico, actividade industrial e costumes commerciaes modernos". Ratificando a constatação de Serva (1924), confirma Lahuerta (1997) que

na década de 20 do século passado, o conceito de modernidade era ambíguo. 0 centenário da independência foi comemorado e o marco simbólico da "nossa modernidade" foi o ano de 1922 porque ele passou a ser identificado com a ruptura com o padrão cultural bacharelesco vigente, e a partir da Semana da Arte Moderna o modernismo torna-se 'um ponto de vista da cultura nacional'. Porém, medindo "pelo metro hegemônico nossa situação ante a Europa, o 'atraso' tornava-se cada vez mais flagrante",

0 retrato escrito que Serva (1924) faz do país tipifica o sentido do 'atraso' nacional.

"Obrigados a entrar na concorrência mundial nós nos sentimos inteiramente contrafeitos e desapparelhados, tendo tudo que aprender [...] Somos um paíz de bacharéis, de doutores, de funccionarios e de burocratas. Quem não é bacharel, doutor, funccionario ou burocrata no Brasil é por via de regra analphabeto".

Para ele, o país estava abandonado porque

o espírito nacional atravessa um período crítico, de transição de uma éra para outra. Há moldes intellectuaes, sociaes e politicos que se quebraram e têm que ser substituidos por outros. Todas as concepções directivas da nossa vida social falharam. Mostraram-se inuteis as estreitas formulas politicas que nos guiaram até aqui. Os nossos estadistas não conseguiram apprehender os factos fundamentaes da vida nacional. 0 nosso meio intelectual tão pouco soube elevar-se a uma altura de onde descortinasse a amplidão colossal dos problemas que fervilham no bojo da nacionalidade. (SERVA, 1924)

Para o autor, a reconstrução nacional deveria ser a grande meta do governo, e a base para 'organizar o povo' se fundamentava em duas questões essenciais: o conhecimento da 'sciencia' e a educação. Portanto "creemos escolas. Assim se eliminará a ignorância, o crime, a miséria"22 . Confirmando esse momento de "crise" que se vivia, diz Delgado de Carvalho (1931) "que onosso seculoéo seculo em quepassam asercapitaes os problemas de ajustamento social. Dahi o impulso que recebem as sciencias sociaes, a Sociologia em especial".

Ainda, segundo Carvalho (1931), eram evidentes as questões sociais que se multiplicavam no país - educação, crimes, alcoolismo - mas, ao mesmo tempo, ele antecipava as 'soluções para um futuro melhor', porque a Ciência, através de determinadas técnicas, poderia promover situações de 'bem estar e segurança da sociedade'. E só a Sociologia, entre as ciências humanas, poderia oferecer as técnicas que outras ciências já

\footnotetext{
${ }^{22}$ Para demonstrar a necessidade da educação no país, ele cita duas frases de Horace Mann (criador das escolas normais nos Estados Unidos). "Não é homem de Estado americano quem não consagra todos os seus esforços à educação do povo" e "A educação é a nossa única salvaguarda política; fora dessa área, não há salvação" (SERVA, 1924).
} 
haviam consagrado. Para Carvalho (1931), além da técnica, o estudo da Sociologia auxiliava a unificação do pensamento.

Apesar das 'soluções' apontadas, o desencantamento atravessa o quadro social revelado por Serva (1924) e Carvalho (1931), permitindo também compreender porque Lahuerta (1997) afirma que

aparecendo como resultado da crise do café e das instituições da Primeira República a exigência de modernização que movimentara as energias da sociedade ao longo dos anos 20 não tinha um sentido muito definido. Pois se é verdadeiro que a intelectualidade passa a pensar o país, propondo reformas e a construção da nação moderna, há que se fazer a ressalva de que tudo isso ocorre de maneira muito ambígua. No fundo a pressão por racionalidade técnica era no Brasil ainda muito incipiente, já que a Ciência continuava a não coordenar de fato nosso real.

Para Ronaldo de Brito, citado por Milton Lahuerta (1997), nossa arte23 (e poderíamos dizer nosso pensamento M.L.) introjetava subjetivamente mais do que vivia objetivamente, a questão da técnica e da ciência. Ela não resultava do choque direto com a estrutura lógica do real e sim de um anseio esperançoso, um pouco angustiado, diante do mundo moderno... Porque, a rigor, gostaríamos, queríamos ser modernos. Aí aparece a verdade deslocada - o simples querer prova que não éramos.

Essa citação, em parte, reafirma a interpretação de Lahuerta (1997, p.96-97) sobre o que significava "modernidade" no Brasil naquele contexto, quando no texto ele constata que "éporisso que a pretensão de ser moderno se desloca paulatinamente para 0 tema nacional". Nessa movimentação cultural, segundo o pesquisador, "em comum, há uma demanda genérica de unificação cultural, um espírito de renovação e atualização que pretende ir além da dimensão estritamente literária e uma preocupação difusa de superar a distância entre o erudito e o popular".

A essência dessas manifestações dos intelectuais modernistas no Brasil, segundo Lahuerta (1997), foi resultante de uma combinação que se delineou nos anos 20 e marcou os anos 30: modernista na reflexão das questões nacionais, com uma postura tradicional na ação. Ou seja, quando foram "ao povo", a preocupação era encontrar matéria-prima pura e autêntica para lhes dar uma forma final mediante um trabalho de síntese eminentemente intelectual, mas, no campo político, aqueles que exerceram suas atividades, tiveram como marcos de ação política a base do pensamento dos partidos oligárquicos. ${ }^{24}$

Das contradições existentes da combinação modernismo-tradicional no período, 0 autor evidencia como ela é apreendida naquele contexto. Para Lahuerta (1997, p.97-

${ }^{23}$ No texto, a questão da arte é tratada, mas sua discussão centraliza-se na literatura.

${ }^{24}$ Lahuerta (1997) cita como exemplos Oswald no PRP; Mário de Andrade e Sérgio Milliet no PD. 
98), basta notar que, pelo menos até30, os próceres do modernismo se mantêm na órbita dos partidos oligárquicos, mas, depois de 30, há uma "politizaçãa" das questões culturais e 0 tema da modernidade fica integralmente subsumido ao da construção de um projeto nacional. Ele acrescenta que, de certa forma, o modernismo como adesão à mudança em todos os sentidos, que não se limitava à arte e à literatura, mas ampliava-se para o campo da reflexão filosófica, política e social, vai sendo paulatinamente frustrado pelo caráter restaurador do processo inaugurado em 30.

E, esclarecendo como essa lógica se reflete nas ações da grande maioria dos intelectuais, ele complementa que em função daquela contradição que marcou 0 pensamento da época

ao longo desses anos, em grande parte da intelectualidade vão se combinar contraditoriamente uma enorme vontade de agir e um sentimento de impotência e isolamento diante do país que a inquieta, mas que não consegue decifrar. Pelo menos entre 1930 e 1935, o potencial de mudanças é muito significativo, embora maior ainda seja a dificuldade de qualquer ação efetiva. (LAHUERTA, 1997).

Com essa referência, entende-se que 0 frenesi pedagógico $0^{25}$ característico desse período retrata, em grande parte, os conflitos de um pensamento modernista-tradicional que marcou profundamente o pensamento dos intelectuais da época, o contexto de "reconstrução nacional" e o processo educacional construído no país.

Portanto, ao associar a singularidade do pensamento da época tratado por Lahuerta (1997); a constatação da predominância dos interesses conservadores que, por meio de dispositivos legais, favoreceram a expansão do ensino acadêmico, explicada por Romanelli (1998) e a afirmativa de Ianni (1988) de que a idéia de Sociologia é contemporânea à idéia de Modernidade porque ambas nasceram na cidade do Mundo Moderno, pode-se visualizar o trânsito da reflexão sociológica em constituição. E, ao mesmo tempo, pode ser atribuída à Sociologia como disciplina escolar uma função social específica.

Naquele processo histórico, tanto o ensino secundário quanto a Sociologia como disciplina escolar constituíram, ao mesmo tempo, mecanismos de controle dos interesses conservadores e simbolos da "modernidade nacional". Afinal, assim como na Inglaterra, na Alemanha e na França, segundo Lepenies (1996), o Estado encontrou na Sociologia o instrumental "científico" para fundamentar, justificar e legitimar suas decisões, pode-se afirmar que o mesmo ocorreu no Brasil.

Concluindo, entende-se a presença do ensino de Sociologia como um dos símbolos daquela modernidade, mas diferente das imagens, como o trem, as máquinas, a iluminação das cidades. Sua presença e força são identificadas no campo das idéias, por meio de seus conteúdos. Mas "idéias dotadas de poder simbólico, persuasivo, denominada

${ }^{25}$ Expressão de Lahuerta (1997). 
de 'idéias forças' (MONARCHA, 1999, p.64). E, como "idéias forças", a disciplina escolar no ensino secundário interferiu nas opções e decisões dos grupos sociais da época, retratando possíveis relações entre o que se ensinava no secundário, a função social desse nível de ensino e as singularidades da cultura do país.

\section{REFERÊNCIAS}

AZEVEDO, Fernando de. A Sociologia no Brasil. In: DICIONÁRIO de Sociologia. Porto Alegre: Globo, 1974. Prefácio.

BRASIL. Decreto n. ${ }^{\circ} 19.890$, de 18 de abril de 1931. Dispõem sobre a organização do Ensino Secundário. Brasília, 1932.

CARVALHO, Delgado de. Sociologia: summarios do curso do sexto anno. São Paulo: F. Alves, 1931.

DISTRITO FEDERAL. Departamento de Educação. Programas de Ciências Sociais. São Paulo: Ed. Nacional, 1934. (Série C)

IANNI, Octávio. A sociologia e o mundo moderno. São Paulo: EDUC, 1988.

LAHUERTA, Milton. Os intelectuais e os anos 20: moderno, modernista, modernização. In: LORENZO, Helena Carvalho de; COSTA, Wilma Peres da (Org.). A década de 1920 e as origens do Brasil moderno. São Paulo: UNESP, 1997.

LEPENIES, Wolf. As três culturas. São Paulo: EDUSP, 1996.

MACHADO, Celso de Souza. 0 ensino da Sociologia na escola secundária brasileira: levantamento preliminar. Revista da Faculdade de educação, São Paulo, v.13, n.1, p.115142, jan.jun. 1987.

MONARCHA, Carlos. Notas sobre educação nacional na "Era Getulina". História da Educação, Pelotas, n.6, p.57-68, out. 1999.

PROGRAMA Integral dos Cursos Complementares. Revista de Sociologia, v.1, n.2, p.42-46, 1939.

ROMANELLI, Otaíza de Oliveira. História da Educação no Brasil. 20. ed. Petrópolis: Vozes, 1998.

SENA, Adalberto Corrêa. Legislação brasileira do ensino secundário: de 1901 a 1939. Rio de Janeiro: Edição da Livraria Central, 1939.

SERVA, Mario Pinto. A educação nacional. Pelotas: Livraria Universal Echenigne, 1924.

VECHIA, Ariclê; LORENZ, Karl Michael (Org.). Programa de ensino da escola secundária brasileira: 1850-1951. Curitiba: Editora do Autor, 1998.

XAVIER, Maria Elizabete et al. História da Educação: a escola no Brasil. São Paulo: FTD, 1994. 